\title{
TEMPLATE FORM FOR RELIABILITY ANALYSIS OF TECHNICAL AND ERGONOMIC REPORTS
}

\author{
Juliana Aparecida Alves de Faria \\ State University of Campinas, Agricultural Engineering Dept., P.O. Box 6011, ZIP Code 13083-875, Campinas-SP, Brazil \\ Corresponding author: julianafariaergonomia@gmail.com
}

\section{Franciele Vieira Rocha}

Federal University of Lavras, Dept. of Sanitary Environmental Engineering, P.O. Box 3037, ZIP Code 37,200-000, Lavras-MG, Brazil

\section{Ednilton Tavares de Andrade}

Federal University of Lavras, Agricultural Engineering Dept., P.O. Box 3037, ZIP Code 37,200-000, Lavras-MG, Brazil

\section{Marco Antônio Gomes Barbosa}

Federal University of Lavras, Dept. of Physical Education, P.O. Box 3037, ZIP Code 37,200-000, Lavras-MG, Brazil

\begin{abstract}
Industrial progress and the consequent increase in job offers in various areas also provide risks related to the performance of functions and the consequent outcome in occupational accidents and illnesses. In most productive sectors, workers face ergonomic problems that generate high risks. To contain these damages, organizations invest in research that generates a report and planning of ergonomic actions. However, there is still no standard for ergonomic reports, which leaves doubts as to the reliability of these documents to current legislation. The objective of this work is the creation of a form, which allows to evaluate in the form of a checklist the quality of the content and the composition of the documents analysis to meet the Regulatory Standard 17 for practical application in companies. The checklist presented technical feasibility of application through the tests performed, the results showed that $38 \%$ compliance with NR 17 (Regulatory Norm) with an average of 15 assertiveness points for the requirements of the standard. The method applied showed that $100 \%$ of the sample of the documents elaborated present absence of parameters and legal technical criteria in its structure. The checklist allowed the importance of the contents of an ergonomic report to be checked quickly and effectively.
\end{abstract}

Index terms: Work, legislation, checklist.

Received: October, 12, 2019 - Accepted: November, 25, 2019

\section{INTRODUCTION}

The work environment is always a scenery of constant research on the conditions of comfort and safety of workers for the performance of work activities. Professionals from several areas work in studies in an attempt to eliminate the potential risks that generate accidents (Pavani, 2006).

Ergonomics is one of the theories, principles, data and methods dedicated to projects to optimize human welfare and overall system performance, and thus naturally increase productivity. This scientific discipline should assist the interaction between the human being and other elements of a second system interpretation of the International Association of Ergonomics (IEA) (IEA, 2009).
According to Veronesi (2014), the ergonomic analysis, also called ergonomic opinion or ergonomic report, is the document capable of ascertaining (quantitatively and qualitatively) the working conditions of a given task, through the application of methods and techniques of observation and qualification of aspects related to work activities. This evaluation should contain an explanation of the overall situation of the tasks, consisting of: workplace, cognitive load, density, work organization, operating mode, rhythms and postures of execution of the activities.

In the studies by Moraes and Andrade (2012), ergonomic analysis is a constructive and participatory process, capable of solving complex problems that require knowledge of 
the tasks, the activity developed to perform and the difficulties faced to achieve the required performance and productivity. Faced with certain demands, the company hires a professional, as proposed by item 12.12 of NR 17, to: "To evaluate the adaptation of the work, the conditions for the psychophysiological characteristics of the workers, it is up to the employer to carry out an ergonomic analysis that should, at least, address the conditions established in this Standard. Therefore, the role of the ergonomist is to present an employment contract in which will be explained the applied methodology, the stages of the analysis, as well as the procedures used."

The aim of the Ergonomic Work Analysis (AET) is to improve the working conditions of workers, with the result that productivity gains or product quality will only increase as a consequence. This expected result, after the working conditions are changed. Unlike labour analyses, whose objectives were to change workers' behaviour, there is a general concern among psychologists and company directors (Ferreira, 2015).

The NR17 Ergonomics (Law no 6514/77 Ordinance $\mathrm{n}^{\circ} 3751 / 90$ ) establishes the obligatory nature of the elaboration and implementation, on the part of all companies that admit employees who are exposed to ergonomic risks. A concept that broadened the regulatory field of ergonomics, previously restricted to advice on how to lift and carry loads, it now includes four more items: work furniture, some working environment conditions, work equipment and, most importantly, work organization which, for the purposes of the standard, includes "work content", "operating modes", rules and working times (Barros Júnior, 2002; Bezerra, 2009).

The implementation and development of an ergonomics management system in a company to mean efficiency and effectiveness shall be supported by guidelines of Occupational Health and Safety Assessment Series (OHSAS 18001) and the manual of application of Standard 17. The OHSAS concept used to model the control and management system was evidenced as a new management concept also to benefit the development and implementation of ergonomics as a process in the organization. Ergonomics is also an early science in the scientific community; many are still unaware of the importance and meaning of "ergonomic analysis of work" (Ferreira, 2015; Moraes and Andrade, 2012; Oliveira et.al, 2010).

Occupational health and safety audits according to Oliveira et. al. (2010) is an effective way to monitor and implement occupational health and safety policies. Consist of surveys of occupational risks, registration of legal and technical non-conformities, and consequent pointing of corrective measures to improve working conditions. This procedure generates an audit report and technical advice, supported by the analysis of the collected data.

As verified by Silva (2014), the ergonomic assessment by the definition of the technical epidemiological social security nexus avoids mistakes and injustices for companies, workers and experts representing the government entity. The sending of the ergonomic analysis of the work is a relevant factor for the proper construction of the type of social security nexus to which the worker is entitled. This document is, therefore, of great value to the company, to the occupational physician and to the INSS.

Ergonomic opinions should be supported by duly qualified professionals with adequate qualification and vast technical knowledge about ergonomics, ensuring the construction of well prepared documents for the contracting organizations and the results of the actions signaled from the report of ergonomic analysis of the work. For Neves et al. (2018) to have the relationship between ergonomic training (knowledge) and ergonomics of the activity as a point of reflection, is a way to contribute to the development of training actions, understanding them as one more way to expand the possibilities of transformation of work situations that contemplate and affirm the health of workers.

The objective of this study is the development and validation of a tool for verifying the conformity of commercialized documents, such as technical and ergonomic reports, thus ensuring respectively the promotion of efficient actions to mitigate the occurrence of accidents and illnesses at work. 


\section{MATERIAL AND METHODS}

This is a methodological research, with quantitative approach, through the construction of an instrument in checklist format. The construction was essentially guided by the content of NR 17, which among others, establishes the mandatory character of the preparation and implementation of ergonomic management in risk prevention programs in work activities by companies regardless of the number of employees.

Also supported by scientific publications discussing health and safety management systems represented by OHSAS 18001 (officially “BS OHSAS 18001: 2007”).

\section{Creating the checklist}

The elaboration of this checklist had as principle the judgment of the technical quality of the ergonomic technical analysis signed by the professionals of the areas: ergonomics, safety and occupational health, for the fulfillment of norms and/or to satisfy requirements in the certification processes.

The checklist was prepared based on valid parameters to assess the quality of services provided by professionals in the areas of ergonomics, safety and occupational health, directing the preparation of documents necessary for compliance with standards and/or for meeting the requirements in the certification processes. In the first stage of the construction of the checklist, the points considered essential in the constitution of an "ergonomic technical report of the work activities" for compliance with NR17 were identified, being these topics the items of comparison of the proposed instrument for verification of the reliability of the content of the documents generated.

Therefore, the checklist also complied with the standard, which establishes the following steps for the compilation of an ergonomic analysis of the work: 1 . Demand analysis and context; 2 . The global analysis of the company; 3 . Analysis of the population of workers; 4 . Definition of the situation work to be studied; 5 . A description of the prescribed tasks, and actual tasks developed to implement them; 6. Establishment of a pre- diagnosis; 7. Systematic observation of the activity, as well as the means available to carry out the task; 8 . The diagnosis (s); 9. Validation of the diagnosis(s); 10 . The design of modifications / changes; 11. The schedule for implementing modifications / changes; 12 . The monitoring of changes / alterations. These steps proposed in the application of the NR 17 manual are reported in the checklist, since they serve as a reference and guidance for the ergonomist to perform his ergonomic analysis of the work, and consequent adaptation of the working conditions to the psychophysiological characteristics of the workers, in order to provide comfort, safety and efficient performance.

The work activities were listed and cited according to aspects related to: handling, lifting, transportation and handling of cargo; environmental working conditions and work organization, item 17.1.1 of NR 17, with sufficient content to also attend audit events, in matters related to ergonomics, providing agility to the process without compromising the organization's routine. Its operationalization, however, was ordered in accordance with the models used by the companies, to evaluate the conformity of the documents in the quality certification processes, based on OHSAS 18001 and conceptual content focused on NR17.

\section{Checklist structure}

The topics were organized in seven parts: I) Of the attributions of the technical responsible persons - in this part the professional responsible for the elaboration of the document is evaluated, based on your technical attributions, as time of performance in the area and recognition of qualification in ergonomics by Brazilian Association of Ergonomics (ABERGO); II) From the textual part of the report objective, description of the groups evaluated (homogeneous group of exposure), description of the investigated population, description of the operations and biomechanical analysis; III) Methods and techniques to support the ergonomic analysis of the work characteristics, tools used by the evaluator, to identify the degree of ergonomic risk, among which, can be classified as: quantitative method, qualitative 
method, protocol (questionnaires) and programs (specific software); IV) general assessment of context, dimensional analysis of environment and furniture, survey and anthropometric comparison of the population of workers, analysis of physical environmental conditions and review of compliance with regulatory standard 17; V) Results: Overview of the ergonomic scenario, ergonomic risk map of the plant, description and detailed location of ergonomic problems (cause and operational impact), ergonomic action plan with indication of the problems, solution and time limit for completion of the proposed activities; VI) Conclusion: demonstration of the degree of overall commitment of the company from the ergonomic point of view; VII) Technical chart: final view of the authors responsible for the ergonomic technical report (Tables 1 and 2).
In the second part there were 07 (seven) items, referring to the topics for description and characterization of the research object and for introductory demonstration of the profile of the evaluated segment, adding 1.0 (one) point for each subject described (Table 1 ).

The third part had 05 (five) options to identify the nature of the methods and techniques chosen by the authors as tools for ergonomic analysis of the sample, adding 1.0 (one) point for each option selected.

In the fourth part composed of 08 (eight) items to describe the general context analyzed, among which: the physical and dimensional characteristics of the environment (layout), the sample profile (anthropometry, biomechanics, demographic data, etc.), and description of the confrontation compliance to regulatory standard 17 (Table 2).

Table 1: Cuttings 1, 2 and 3 of the checklist, to validate the quality of the material of the ergonomics services (AET Certification).

\begin{tabular}{|c|c|c|}
\hline \multicolumn{2}{|r|}{ ITENS } & \multirow[t]{2}{*}{ Weight Note } \\
\hline 1 & PART I OF THE TASKS OF THE TECHNICAL MANAGERS & \\
\hline 1.1 & $\begin{array}{l}\text { The responsible professionals must have legal support (provided by law or resolution) for the } \\
\text { issue of AET (ergonomic analysis of the work), based on Regulatory Standard } 17 \text {. } \\
\text { For ABERGO only professionals certified in a lato sensu post-graduation course, of at least } 360 \\
\text { hours, can sign the AET document }\end{array}$ & 1.0 \\
\hline 1.2 & Professional certified by ABERGO & 1.0 \\
\hline 1.3 & $\begin{array}{l}\text { Professional with a period of performance and experience in the area, equal or superior to } 10 \\
\text { years }\end{array}$ & 3.0 \\
\hline 1.3.1 & $\begin{array}{l}\text { Professional with a period of performance and experience in the area, equal or superior to } 05 \\
\text { years. }\end{array}$ & 2.0 \\
\hline 1.3 .2 & $\begin{array}{l}\text { Professional with a period of performance and experience in the area, equal or superior to } 02 \\
\text { years. }\end{array}$ & 1.0 \\
\hline 2 & \multicolumn{2}{|l|}{ PART II TEXTUAL PART OF THE DOCUMENT (REPORT DESCRIPTIVE) } \\
\hline 2.1 & Objective AET & 1.0 \\
\hline 2.2 & Description Homogeneous Exhibition Group (GHE) & 1.0 \\
\hline 2.3 & Description of the investigated population & 1.0 \\
\hline 2.4 & Analytical Description Operational Cycle & 1.0 \\
\hline 2.5 & $\begin{array}{l}\text { Description of the criteria for quantifying the risk intensity } \\
\text { of biomechanical and environmental factors }\end{array}$ & 1.0 \\
\hline 2.6 & $\begin{array}{l}\text { Verification of biomechanical and environmental risk factors for } 100 \% \\
\text { of the activities (by statistically sufficient sampling cuts) }\end{array}$ & 1.0 \\
\hline 2.7 & $\begin{array}{l}\text { Enable the identification of the specific risk of each body zone (lumbar spine, } \\
\text { dorsal spine, cervical spine, shoulder, elbow, wrist and hands). }\end{array}$ & 1.0 \\
\hline 3 & \multicolumn{2}{|l|}{ PART III METHODS AND TECHNIQUES FOR UNDERPINNING ERGONOMIC WORK ANALYSIS } \\
\hline 3.1 & Application of at least 01 qualitative method & 1.0 \\
\hline 3.2 & Application of at least 01 quantitative method & 1.0 \\
\hline 3.3 & Application of at least 01 semi-quantitative method & 1.0 \\
\hline 3.4 & Application of at least 01 protocol & 1.0 \\
\hline 3.5 & Application of at least 01 specific software for biomechanical analysis & 1.0 \\
\hline
\end{tabular}


Table 2: Cuttings 4, 5, 6 and 7 of the checklist, to validate the quality of the material of the ergonomics services (AET Certification).

\begin{tabular}{|c|c|c|}
\hline 4 & PART IV EVALUATION & Weight Note \\
\hline 4.1 & Analysis and metric description of furniture and utilities by Workstation / 100\% sampling & 1.0 \\
\hline 4.2 & $\begin{array}{l}\text { Analysis and metric description and division of areas (environment) layout of ergonomic risk } \\
\text { exposure by Workstation / 100\% sampling }\end{array}$ & 1.0 \\
\hline 4.3 & Biomechanical descriptive analysis by Workstation / 100\% sampling & 1.0 \\
\hline 4.4 & Descriptive and statistical analysis of posture adoption per Workstation / 100\% sampling & 1.0 \\
\hline 4.5 & Anthropometric reading of the population under investigation & 1.0 \\
\hline 4.6 & Exposure of results of ergonomic methods and techniques (tools) applied for risk assessment & 1.0 \\
\hline 4.7 & NR17 Confrontation - checklist survey considering standard & 1.0 \\
\hline 4.8 & Analysis of physical environmental conditions PPRA (NR9 / NR17) & 1.0 \\
\hline 4.9 & Compliance Review NR17 & 1.0 \\
\hline 5 & \multicolumn{2}{|l|}{ PART V RESULTS } \\
\hline 5.1 & Overview Ergonomic Risk Plant ( Ergonomic Risk Map) & 2.0 \\
\hline 5.2 & Ergonomic Action Planning PAE & 2.0 \\
\hline 5.3 & Ergonomic Prescription & 2.0 \\
\hline 6 & \multicolumn{2}{|l|}{ PART VI FINALISATION } \\
\hline 6.1 & Ergonomic Assessment Conclusion & 2.0 \\
\hline 7 & \multicolumn{2}{|l|}{ PART VII TECHNICAL SEAL } \\
\hline 7.1 & Signature of the Technical Manager / Ergonomist & 3.0 \\
\hline 7.2 & Signature of the Technical Responsibility Annotation Officer & 2.0 \\
\hline 7.3 & Signature of the Technical Manager Hired Company & 1.0 \\
\hline 7.4 & Signature of the Technical Manager Contracting Company & 1.0 \\
\hline & SUM (cutout tables 1 and 2) & 41 \\
\hline
\end{tabular}

The first evaluative part was composed of 05 (five) alternatives with weights between 1.0 (one) and 3.0 (three) points, for classification of titles and experience of the professional responsible for the analyses performed. Adding extra points for the specialized professionals and ergonomists certified by ABERGO. Regarding the qualification related to the time of professional experience, a maximum score of three points was given to the professionals with a period of experience in the area, equal or superior to 10 (ten) years, two points for 05 (five) years of experience and 01 (one) point for professionals with experience equal or superior to 02 (two) years in the area.

The fifth part contains 3.0 (three) items, each item has a value equal to 2.0 (points), the first presents an overview of the analysis and shows the level of exposure of the company according to the degree of ergonomic risk resulting from the methods applied. Illustrated on a map of ergonomic risk, this is the schematic design of the environment (floor plan) with indication of risks in the form of signs, being red for places where there is high ergonomic risk, yellow for medium risk and green for low risk (Figure 2). The second item is the description of the action plan, pointing out the problems and respective explanation of the cause nexus, and proposing a solution with defined deadlines for completion of the activities. The third item in this part is the ergonomic prescription, which synthesizes the pointing out of the problems identified by the evaluator.

In the sixth part of the report is contextualized the ergonomic assessment, which is the summary of the points of conformities and ergonomic nonconformities, discovered by the assessment, this item adds 2.0 (two) points for quality analysis of the document.

The seventh part concludes the document with the place dedicated to the signature of the technical managers, the first signature represents the ergonomist with the highest sum of points (3 points more), thus recognizing the importance of these professionals in processes 
of this nature. In sequence, the professional responsible for the Technical Responsibility Annotation (ART) is placed, which must have competence to register the material and respective legal support, adding 2.0 (two) points to the quality evaluation of the document, and 01 (one) point signatures of the responsible of the contracting party (company) and contracted party (ergonomist).

For all items, weights ranging from a minimum of 1.0 (one) to a maximum of 3.0 (three) points were dedicated. Having higher score the topics that are essential for composing an ergonomic report.

Therefore, to be considered a document with technical validity, the final score must have at least $90 \%$ of scored items, minimum 37 points, in this case the document is considered "document with total technical validity of compliance NR17", for reports whose sum of points is greater than or equal to 25 , corresponding to $60 \%$ or more assertions, the document will be classified as "Document with partial technical validity of compliance NR17". and, if the score is less than or equal to $50 \%$, less than or equal to 21 points, the classification is of a "document without technical validity of compliance NR17" (Table 3).

Table 3: Classification Scores by checklist score of reports and ergonomic reports according to NR17.

\begin{tabular}{|c|c|c|}
\hline Punctuation & $\%$ & Classification \\
\hline$\geq 37$ & $\begin{array}{l}\geq 90 \% \text { Document } \\
\text { NR17 }\end{array}$ & in accordance with the \\
\hline$\geq 25$ & $\begin{array}{l}\geq 60 \% \text { Document i } \\
\text { the NR17 }\end{array}$ & in partial compliance with \\
\hline$\leq 21$ & $\begin{array}{l}\leq 50 \% \text { Document } \mathrm{n} \\
\text { NR17 }\end{array}$ & not in compliance with the \\
\hline
\end{tabular}

After completion of the initial version of the checklist, the tests of application and analysis of the results began. We sought to verify in practice the points of compliance, from the documents presented as reports and ergonomic reports, to the requirements of standards in force in the environment. In this stage, systematized searches were made in electronic databases. The search term used in the databases was "Ergonomic Analysis of Work".
Searches were not limited by language or date of publication. The last search was conducted in 2019. For the selection of studies, reports made by Brazilian organizations were used as inclusion criteria. Academic papers, theses, dissertations and course completion papers were also considered. The selection was initially made through titles, followed by abstracts, and when selected, by complete reading of the reports.

The objective of this action was to evaluate the effectiveness of the checklist, to verify the quality and compliance of the reports and reports practiced in the market, with the requirements of NR17.

\section{RESULTS AND DISCUSSION}

In the proposed molds, the electronic search returned 8 (eight) reports, based on the key words mentioned above. This number is restricted, perhaps justified by the content of these documents, composed of confidential information that may compromise the company, depending on the purpose for which it is used, a reason that prevents the disclosure of materials of this nature.

After selection, the reports were submitted to the checklist for conformity assessment to NR17. One report scored 25 points, which means $60 \%$ assertiveness and is therefore considered "document with partial technical validity of conformity to NR17". The remaining seven did not reach the minimum level of $50 \%$, equivalent to 21 points, to be considered valid in the test classification criteria. Two reports achieved $24 \%$ compliance, with only 10 points, and five scored between 12 and 20 points, classified as "document without compliance validity to NR17", according to the criteria of the checklist under test (Table 4).

The application of the checklist showed the importance of both theoretical and methodological guidance and the participation of an ergonomics specialist to ensure technical quality during the preparation of ergonomic reports. It was also pointed out that an ergonomic management system starts with the construction of the ergonomic analysis, which needs to be technically sufficient 
to give results and the return expected by the company (Moraes and Andrade, 2012; Ferreira, 2015).

The $\mathrm{R} 5$ model report, which is equivalent to $12 \%$ of the sample, obtained a partial compliance average within the criteria established in NR17. The others, $87 \%$ of the ergonomic reporting templates, did not meet the average compliance rating. No report was able to achieve $90 \%$ satisfaction of the requirements with a score greater than or equal to 37 points for total satisfaction of the standard (Figure 1).

Ergonomic management system meets the objective of providing the organization with the elements of an effective method for the development of ergonomics within a health and safety program, based on OHSAS 18001, in order to help it achieve its objectives, thus being able to demonstrate progressive improvements in the reduction of its work accidents and occupational diseases. It is therefore essential to consider its premises during the process of construction and modeling of documents to assess the management methods adapted by companies (APCER, 2010).

The results showed a great deficiency in the ergonomic analyses to tell about the working conditions, leaving to be desired also in the application of methods and techniques for quantification and qualification of aspects related to work activities, contradicting the basic composition of an ergonomic assessment as stated by Veronesi (2014).

In the sample used in this research it was not mentioned the technical expertise of the authors responsible for preparing the reports, a point that also compromises the reliability of these documents. According to Neves et al. (2018), comprehensive knowledge in ergonomics is necessary to ensure an analysis made within the standards of compliance with the standard to provide data for safety adjustments in work tasks.

Table 4: Results of the checklist application in documents entitled as reports and/or ergonomic reports.

\begin{tabular}{|c|c|c|c|}
\hline $\begin{array}{l}\text { List of } \\
\text { analyzed } \\
\text { reports }\end{array}$ & Identification of Companies & $\begin{array}{c}\text { Checklist } \\
\text { Score }\end{array}$ & Classification \\
\hline $\mathrm{R} 1$ & $\begin{array}{c}\text { Company: Federal Savings Bank } \\
\text { Elaboration: Electrical and Work Safety Engineer } \\
\text { Date prepared: May } 2012\end{array}$ & 15 & $\begin{array}{l}\text { Document not } \\
\text { in compliance } \\
\text { with NR17 }\end{array}$ \\
\hline $\mathrm{R} 2$ & $\begin{array}{c}\text { Company: Ultracargo } \\
\text { Elaboration: Corporate Coordinator of Health, Hygiene and Safety at Work } \\
\text { Date prepared: December } 2016\end{array}$ & 16 & $\begin{array}{l}\text { Document not } \\
\text { in compliance } \\
\text { with NR17 }\end{array}$ \\
\hline $\mathrm{R} 3$ & $\begin{array}{l}\text { Company: Federal Institute - Green Field } \\
\text { Elaboration: Enfemed Medical Center } \\
\text { Date prepared: August } 2016\end{array}$ & 20 & $\begin{array}{l}\text { Document not } \\
\text { in compliance } \\
\text { with NR17 }\end{array}$ \\
\hline $\mathrm{R} 4$ & $\begin{array}{l}\text { Company: Chemical Company Ltda } \\
\text { Elaboration: Occupational Safety Advisory Company } \\
\text { Date prepared: August } 2006\end{array}$ & 17 & $\begin{array}{l}\text { Document not } \\
\text { in compliance } \\
\text { with NR17 }\end{array}$ \\
\hline R5 & $\begin{array}{c}\text { Company: Hospital and Emergency Room August } 28^{\text {th }} \\
\text { Elaboration: SASMET -Occupational Safety and Medicine Advisory Service } \\
\text { Date prepared: October } 2013\end{array}$ & 25 & $\begin{array}{l}\text { Document in } \\
\text { partial compliance } \\
\text { with NR17 }\end{array}$ \\
\hline R6 & $\begin{array}{c}\text { Company: COVISA - Health Surveillance Coordination, City Hall - SP } \\
\text { Elaboration: Physician at Work } \\
\text { Date prepared: February } 2013\end{array}$ & 10 & $\begin{array}{l}\text { Document not } \\
\text { in compliance } \\
\text { with NR17 }\end{array}$ \\
\hline R7 & $\begin{array}{c}\text { Company: João Felisberto de Miranda and Cia Ltda } \\
\text { Elaboration: Athenas Occupational Safety Management } \\
\text { Date prepared: March } 2017\end{array}$ & 12 & $\begin{array}{l}\text { Document not } \\
\text { in compliance } \\
\text { with NR17 }\end{array}$ \\
\hline $\mathrm{R} 8$ & $\begin{array}{c}\text { Company: Rothenberg Perfumes and Cosmetics Shop Ltda } \\
\text { Elaboration: Not identified } \\
\text { Date prepared: Not identified }\end{array}$ & 10 & $\begin{array}{l}\text { Document not } \\
\text { in compliance } \\
\text { with NR17 }\end{array}$ \\
\hline
\end{tabular}




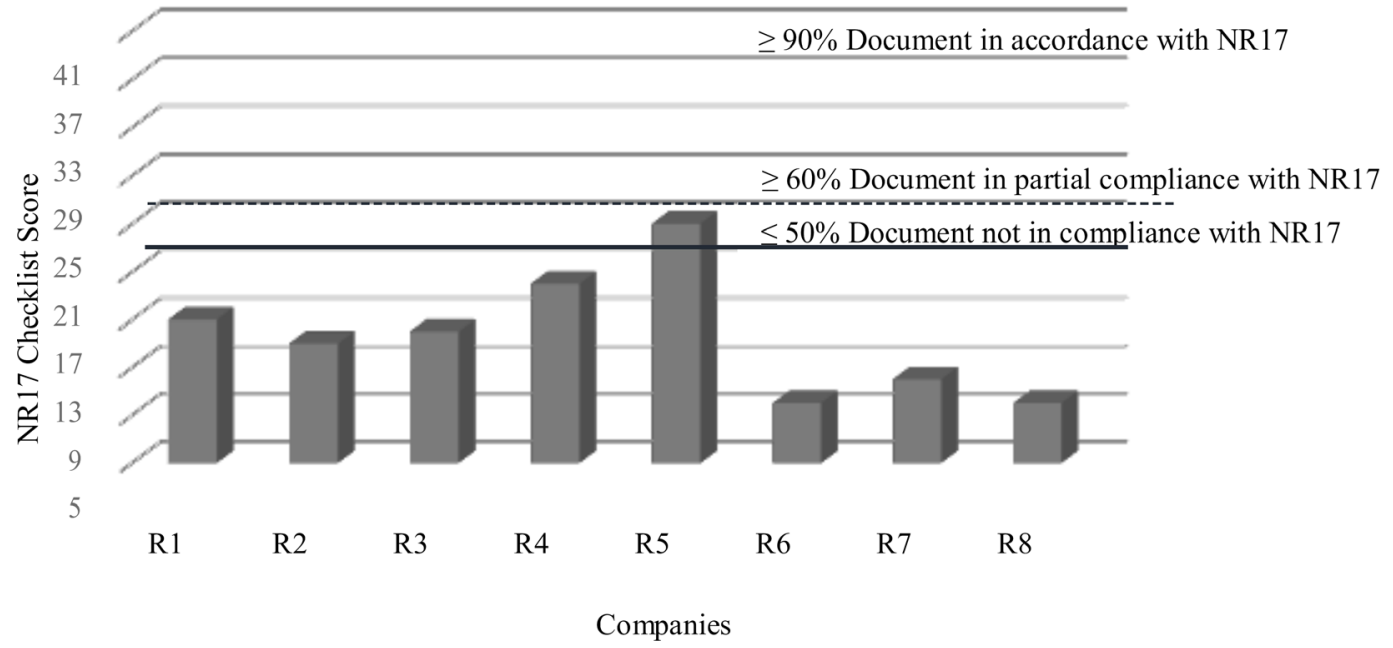

Figure 1: Score for classification of Ergonomic Technical Analysis according to NR17 compliance checklist.

\section{CONCLUSIONS}

The ergonomics reports submitted to the checklist showed 38\% compliance with NR 17, with an average of 15 assertiveness points for the items required in the standard assessment. The method applied showed that $100 \%$ of the sample of the documents elaborated present absence of parameters and legal technical criteria in its structure.

The present article can be used as a proposal for validating a form with information and references that allow verification of the importance of the content of an ergonomic report in a fast and effective manner.

It is hoped that the application of this checklist can provide important data for the construction of useful documents enabling the development of efficient occupational health and safety management systems.

\section{REFERENCES}

APCER. Guia Interpretativo OHSAS 18001:2007 NP 4397. APCER, 2010.

FERREIRA, L. L. Sobre a Análise Ergonômica do Trabalho ou AET. Revista Brasileira Saúde Ocupacional. São Paulo, 40 (131): 8-11, 2015. São Paulo, 40 (131): 8-11, 2015.

BARROS JÚNIOR, J. C. B. Manual de Aplicação da Norma Regulamentadora $N^{0}$ 17. 2 ed. Brasília: MTE, SIT, 2002. 101p.
BEZERRA, M.L.S.; NEVES, E. B. Application of Regulatory Norm 17 (NR17) in private physiotherapy rehabilitation services in Rio de Janeiro and Niteroi municipalities.. Collective Health Booklet. Rio de Janeiro, 17 (4): 923 - 937, 2009

MORAES, B.; ANDRADE, V. S. Implantation of an ergonomics administration system in a company: report of an occupational therapist specialist in ergonomics. Work, 41:2637-42, 2012.

NEVES, M. Y. et al. Action training: a reading of the contributions of Activity Ergonomics. Fractal: Journal of Psychology, 30(2): 66-68, 2018.

OLIVEIRA, O.J. et al. Occupational health and safety management in automotive battery companies: a study to identify good practices. Production, 20(3):481-490, 2010.

SILVA, J.A.R.O.; SARDÁ, S.E. Expert evidence produced by different kinds of professionals and the law that regulates doctors' practice: in search of an interpretation that takes into account the unity of the system and the effectiveness in providing lega remedy. LTr Magazine : labour legislation, v. 78, n. 2, p. 162178, fev. 2014.

VERONESI, J.J. Physiotherapy of Work: Caring for the Functional Health of the Worker. 2.ed. São Paulo: Andreoli, 2014. 358p. 